\title{
Technique for the management of anterior flail chest
}

\author{
NATALINO GUERNELLI, ROMANO B BRAGAGLIA, ANTONIO BRICCOLI, \\ MARIO MASTRORILLI, AND ROBERTO VECCHI
}

\author{
From the Clinica Chirurgica, University of Bologna, Bologna, and from the Institute of \\ Surgical Pathology, University of Modena, Italy
}

ABSTRACT A technique for the management of anterior flail chest consisting of osteosynthesis and the positioning of two long Kirschner wires behind the sternum in the form of a St Andrew's cross is described. The procedure is easy to perform, the patient is ambulant early, and the results are good.

Anterior flail chest is a particularly dangerous lesion since it interferes seriously with the dynamics of both sides of the chest. The methods usually used in the management of flail chest are osteosynthesis, traction and suspension, and mechanical ventilation. Osteosynthesis and rib fixation give inadequate fixation. Traction and suspension may be sufficient in managing the abnormal movement, but the patient is immobilised for a long time.

Internal dynamic stabilisation with a mechanical respirator has solved many problems but has created new ones, such as alterations in lung tissues from prolonged pressure ventilation, tracheal strictures, infection, and long-term immobilisation. It also needs skilled staff.

Since the beginning of 1971 we have used internal stabilisation for managing anterior flail chest (Guernelli et al, 1971). As soon as resuscitative measures have been started the patient undergoes anterolateral thoractomy and osteosynthesis of the fractured ribs and the fractured sternum. Two long Kirschner wires are then positioned to form a St Andrew's cross behind the sternum, with the point of intersection behind the fracture. The entrances of the "skewers" below and the exits above the flail segment all rest on firm bone (fig 1). No traction is necessary because the stability of the flail segment is remarkable. The patient is ambulant shortly after the operation.

This internal fixation has enabled us to avoid the use of positive-pressure ventilation.

We have skewered five cases of anterior flail chest. In one case parallel wires were used, but the final position of the fragments was not as satisfactory as when the pins were used in the St Andrew's cross form (fig 2). Of the five patients only two required postoperative mechanical

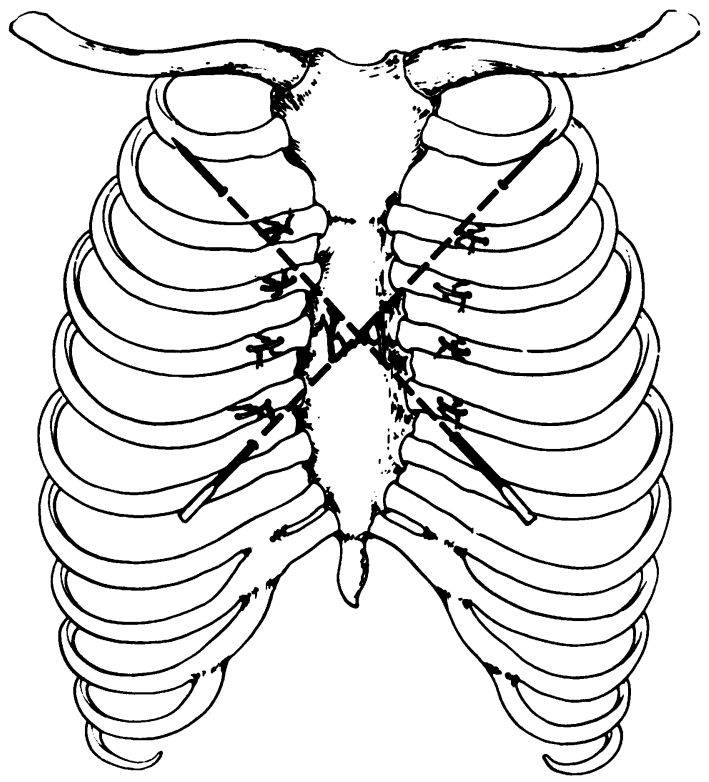

Fig 1 Scheme of positioning of the "skewers" in a St Andrew's cross.

ventilation, one for 11 hours and the other for 19 hours. All made satisfactory recoveries.

\section{Reference}

Guernelli, N, Mastrorilli, M, and Martinelli, G (1971). Nostro orientamento nella terapia del lembo parietale mobile anteriore. Archivio ed Atti della Società Italiana di Chirurgia, II, 73rd Congress. Rome.

Requests for reprints to: Dr R B Bragaglia, Clinica Chirurgica, University of Bologna, Bologna. 


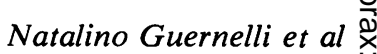

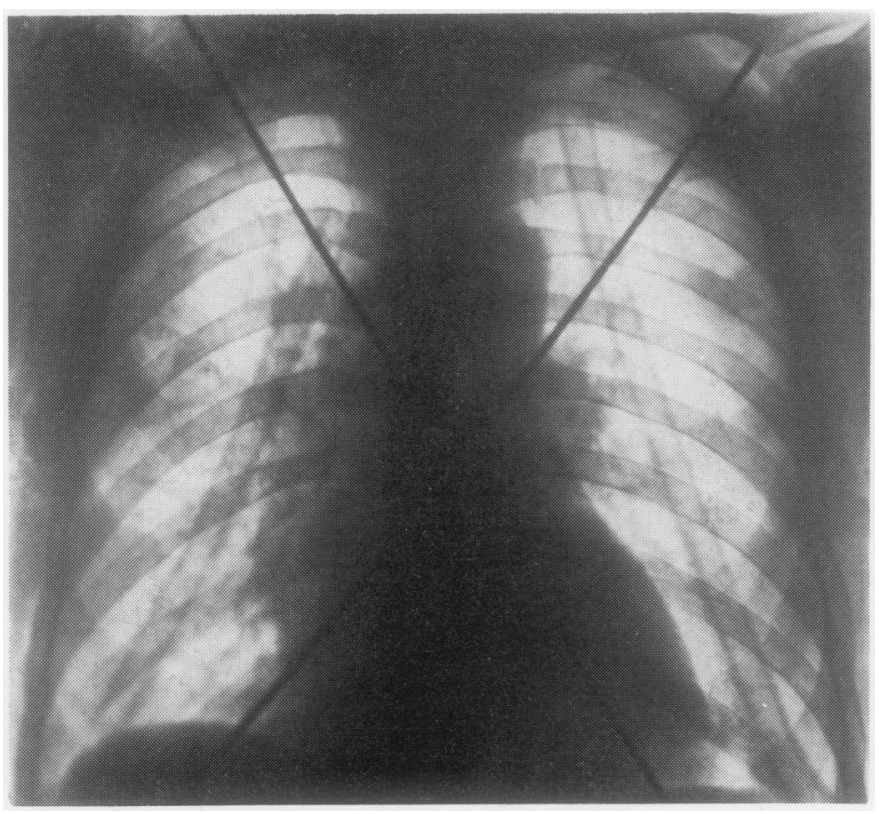

Fig 2 Case 1. Chest radiograph after positioning Kirschner pins in our usual manner. 